\title{
Preresection serum C-reactive protein measurement and survival among patients with resectable non-small cell lung cancer
}

\author{
Marco Alifano, MD, PhD, ${ }^{\mathrm{a}, \mathrm{e}}$ Pierre E. Falcoz, $\mathrm{MD}, \mathrm{PhD},{ }^{\mathrm{f}}$ Valérie Seegers, $\mathrm{MD},{ }^{\mathrm{b}}$ \\ Nicolas Roche, MD, PhD, ${ }^{\mathrm{c}}$ Olivier Schussler, MD, PhD, ${ }^{a}$ Mohamad Younes, $\mathrm{MD},{ }^{\mathrm{e}}$ \\ Filippo Antonacci, MD, ${ }^{\mathrm{f}}$ Patricia Forgez, PhD, ${ }^{\mathrm{e}}$ Agnes Dechartres, MD, ${ }^{\mathrm{b}}$ Gilbert Massard, MD, ${ }^{\mathrm{f}}$ \\ Diane Damotte, MD, PhD, ${ }^{\mathrm{d}, \mathrm{g}, \mathrm{h}, \mathrm{i}}$ and Jean-François Régnard, $\mathrm{MD}^{\mathrm{a}}$
}

Objective: This study aimed to determine whether preresection serum CRP level independently predicts survival among patients with resectable non-small cell lung cancer.

\begin{abstract}
Methods: Clinical, pathologic, and laboratory data from 300 patients operated on for non-small cell lung cancer in a single institution were studied in univariate and multivariate survival analyses. Validation was sought in another cohort of 68 similar patients from another institution.
\end{abstract}

\begin{abstract}
Results: In the main cohort, preoperative CRP value was $3 \mathrm{mg} / \mathrm{L}$ or lower in 136 patients $(45.3 \%)$, between 4 and $20 \mathrm{mg} / \mathrm{L}$ in $89(29.7 \%)$, and greater than 20 in $64(21.3 \%)$. CRP level was significantly associated with chronic bronchitis, hypoalbuminemia, pathologic stage, and peritumoral vascular emboli. Overall, 5-year survivals of patients with preoperative CRP $3 \mathrm{mg} / \mathrm{L}$ or lower, between 4 and $20 \mathrm{mg} / \mathrm{L}$, and greater than $20 \mathrm{mg} / \mathrm{L}$ were $55.6 \%, 45.6 \%$, and $40.0 \%$, respectively $(P=.0571)$. In multivariate analysis, CRP level greater than 20 was significantly associated with survival, but with significant interaction between CRP level and disease stage $(P=.02)$. Patients in stage I or II disease with CRP levels greater than 20 had worse survival than did patients with undetectable CRP (adjusted hazard ratio, 1.874; 95\% confidence interval, 1.039-3.381); the difference was not significant in stages III and IV. In the validation series, CRP level greater than $20 \mathrm{mg} / \mathrm{L}$ also predicted worse survival $(P=.018)$.
\end{abstract}

Conclusions: Preoperative CRP level greater than $20 \mathrm{mg} / \mathrm{L}$ is significantly associated with worse survival than undetectable CRP in patients with stage I or II non-small cell lung cancer. (J Thorac Cardiovasc Surg 2011;142:1161-7)

The role of systemic inflammation in patients with cancer is being increasingly investigated. ${ }^{1,2}$ Proinflammatory cytokines and associated growth factors are involved in carcinogenesis through their effects on tumor cell growth, survival, proliferation, and migration. ${ }^{3}$ In addition, tumor cells themselves release inflammatory cytokines. ${ }^{3}$ It has been shown that slight elevation of inflammatory markers is associated with the occurrence of non-small cell lung cancer (NSCLC). ${ }^{4}$ Lung cancer is frequently associated with chronic obstructive pulmonary disease, which increases the risk of lung cancer's occurrence independently

\footnotetext{
From the Departments of Thoracic Surgery, ${ }^{\mathrm{a}}$ Clinical Epidemiology, ${ }^{\mathrm{b}}$ Chest Disease, ${ }^{\mathrm{c}}$ and Pathology, ${ }^{\mathrm{d}}$ Hôtel-Dieu Hospital, APHP, Université Paris Descartes, Paris, France; Inserm UMRS 938, ${ }^{\text {e }}$ Centre de Recherche Saint Antoine, Paris, France; Department of Thoracic Surgery, ${ }^{\mathrm{f}}$ Centre Hospitalier Universitaire de Strasbourg, France; Inserm UMRS 872, ${ }^{\mathrm{g}}$ Centre de Recherche des Cordeliers, Paris, France; Inserm UMRS 872, ${ }^{\text {h }}$ Université Pierre et Marie Curie-Paris 6, Paris, France; and Inserm UMRS 872, ${ }^{\mathrm{i}}$ Université Paris Descartes, Paris, France.

Disclosures: Authors have nothing to disclose with regard to commercial support.

Received for publication Feb 6, 2011; revisions received June 24, 2011; accepted for publication July 14, 2011; available ahead of print Aug 29, 2011.

Address for reprints: Marco Alifano, MD, PhD, Service de Chirurgie Thoracique, Hôtel-Dieu Hospital, 1 Place du Parvis de Notre Dame, 75181 Paris, France (E-mail: marco.alifano@htd.aphp.fr).

$0022-5223 / \$ 36.00$

Copyright (c) 2011 by The American Association for Thoracic Surgery doi:10.1016/j.jtcvs.2011.07.021
}

of smoking. ${ }^{5}$ Chronic obstructive pulmonary disease is also associated with systemic inflammation and shares several mechanisms with lung cancer, including airways inflammation protease/antiprotease imbalance, oxidative stress, and abnormal repair mechanisms. ${ }^{6}$ In chronic obstructive pulmonary disease, markers of systemic inflammation are related to survival and nutritional status. ${ }^{6}$

Serum C-reactive protein (CRP), a well known and routinely measured marker of chronic inflammation, is produced in the liver in response to elevated levels of proinflammatory cytokines, in particular interleukin 1, tumor necrosis factor $\alpha$, and mainly interleukin $6{ }^{7}$ In NSCLC, the tumoral cells are able to release interleukin 6 and tumor necrosis factor $\alpha$, as assessed by experimental studies on lung cancer cell lines and expression studies on resected specimens. $^{8-10}$

CRP has been identified as a prognostic factor in several tumors. ${ }^{11,12}$ Its relationship with prognosis has also been suggested in advanced NSCLC ${ }^{13,14}$ and, to a lesser extent in resectable disease. ${ }^{15,16}$ In that context, CRP levels are related to several clinicopathologic features (mainly tumor size), which makes it difficult to determine their respective roles in survival. ${ }^{15}$

The aim of this study was to determine whether preresection serum CRP level is an independent predictor of survival 


\section{Abbreviations and Acronyms \\ $\mathrm{CI}=$ confidence interval \\ $\mathrm{CRP}=\mathrm{C}$-reactive protein \\ $\mathrm{CT}=$ computed tomography \\ NSCLC $=$ non-small cell lung cancer}

for resected NSCLC. We analyzed data of 2 cohorts of consecutive patients undergoing surgery for NSCLC in 2 French Institutions.

\section{MATERIALS AND METHODS}

A 2-step process was followed. First, data from a prospective cohort of all consecutive patients who underwent lung resection at Hôtel-Dieu University Hospital in Paris were analyzed (main cohort). Then generalizability of results was assessed in another cohort of patients with similar inclusions characteristics cared for in another center (validation cohort).

Informed consent was obtained from all patients. The research was conducted according to recommendations outlined in the Helsinki Declaration. Institutional review board approval was obtained (CPP Ile de France II, No. 2008-133).

Serum CRP levels were measured in laboratories of both institutions by nephelometry as a part of routine presurgical laboratory examinations. Lower detection limit was $3 \mathrm{mg} / \mathrm{L}$, which was chosen as a cutoff. On the basis of clinical relevance, a second cutoff was set at $20 \mathrm{mg} / \mathrm{L}$.

Long-term survivals of patients in both cohorts were assessed retrospectively by direct telephonic patient or family (in the case of deceased patients) interviews. When no clinical follow-up was available, information on vital status was obtained through the municipality of birth of the patient.

\section{Main Cohort}

All patients undergoing major lung resection for NSCLC between June 15, 2001, and May 15, 2002, in the Thoracic Surgery Department of HôtelDieu Hospital, Paris, France, were included in this study. Patients were excluded if any of the following features were present: antibiotic treatment in the week before hospital admission, fever with temperature greater than $38^{\circ} \mathrm{C}$, purulent sputum, or lung consolidation. Patients characteristics, treatment procedures, and short-term outcomes were prospectively collected with a standardized case report form, which was initially designed to study the determinants of postoperative respiratory complications. ${ }^{17,18}$ For the purposes of this study, the variables shown in Table 1 were analyzed. In particular, we recorded the following: age, sex, body mass index, medical history including tobacco consumption, lung function, indication for lung resection, CRP level, white blood cell count, chest radiography, and albumin and prealbumin levels. Data on long-term outcomes were obtained retrospectively.

\section{Validation Cohort}

The validation clinical series was obtained by retrospective analysis of clinical, pathologic, and laboratory files of patients undergoing surgery for NSCLC between April 1, 2005, and May 31, 2006, in the Department of Thoracic Surgery of Strasbourg University Hospital, France.

\section{Patient Management}

In both centers, the patient management was similar. Staging protocol involved chest radiography, fiberoptic bronchoscopy, thoracic and upper abdominal computed tomography (CT). Cerebral CT scans were performed in the presence of neurologic symptoms or if $\mathrm{N} 2$ disease was suspected. Positron emission tomographic scans were seldom performed before 2006 at either institution.

\section{Mediastinal Lymph Node Assessment and Neoadjuvant Chemotherapy}

In the case of clinical suspicion of $\mathrm{N} 2$ disease (lymph node short axis $>1$ $\mathrm{cm}$ on CT scan), mediastinal staging was carried out by either transbronchial needle aspiration or, more frequently, mediastinoscopy. In rare cases the disease was staged $\mathrm{N} 2$ on the basis of $\mathrm{CT}$ and positron emission tomographic scans without histologic confirmation because of the presence of bulky homolateral lymph nodes. If N2 disease was confirmed, neoadjuvant chemotherapy was administered. Patients were then considered to have operable disease in the presence of clinical response or stable disease. In cases of progressive disease, surgery was not proposed and the patient was excluded from this analysis.

\section{Surgical Procedure, Pathologic Data, and Adjuvant Treatment}

Surgery was carried out through standard posterolateral thoracotomy. Full nodal dissection was carried out in all cases. Collected pathologic data included histologic type; T, N, and M parameters; and tumor stage according to the 1997 Union for International Cancer Control, American Thoracic Society, and American College of Chest Physicians lung cancer staging system. Information about the presence of vascular or lymphatic tumor emboli was also collected. Adjuvant radiotherapy or chemotherapy was proposed on an individual basis after multidisciplinary evidencebased discussions with patients under the care of their referring physicians.

\section{Data Analysis}

Characteristics of patients were described with numbers and percentage. The characteristics associated with CRP levels were identified with $\chi^{2}$ or Fisher Exact tests as appropriate. Survival was described according to the Kaplan-Meier method. Survivals were compared according to the characteristics of participants with log-rank tests. All the variables associated with survival with a $P$ value lower than .2 in univariate analysis were entered into the multivariate analysis with the Cox model. To further control for confounding, we also adjusted on a propensity score of having a CRP level greater than $20 \mathrm{mg} / \mathrm{L}$. To do so, we performed a logistic regression model with CRP level greater than $20 \mathrm{mg} / \mathrm{L}$ as the dependent variable with all variables that were recorded in a sufficient number of patients.

The multivariate analysis also included an interaction term between CRP level and stage of the cancer to assess whether the effect of CRP varied with stage of cancer. This interaction proved significant, so we have presented the results separately for stages I and II and stages III and IV.

All the analyses were performed with the software R 2.10.1, a language and environment for statistical computing. (R Foundation for Statistical Computing, Vienna, Austria).

\section{RESULTS \\ Main Cohort}

Among 347 patients undergoing lung resections for NSCLC between June 2001 and May 2002 at Hôtel-Dieu Hospital, 47 were excluded from the analysis: 29 with infection at time of surgery and 18 because they were not living in France (so follow-up was limited). Altogether, 300 patients were analyzed.

Preoperative, surgical, and pathologic data. An endobronchial tumor was seen at fiberoptic bronchoscopy in $34.4 \%$ of cases; $8.5 \%$ of patients had a cavitary lesion on preoperative CT scan. Induction treatments had been carried out in 80 patients (68 chemotherapy, 12 radiotherapy). Main indication for preoperative induction therapy was N2 
TABLE 1. Patient characteristics (main cohort)

\begin{tabular}{|c|c|c|c|c|c|}
\hline & \multirow[b]{2}{*}{ Total $(\mathbf{N}=\mathbf{3 0 0})$} & \multicolumn{3}{|c|}{ C-reactive protein level $(\mathrm{mg} / \mathrm{L})$} & \multirow[b]{2}{*}{$P$ value } \\
\hline & & $\leq \mathbf{3}(\mathbf{N}=136)$ & 4-20 $(\mathrm{N}=89)$ & $>20(N=64)$ & \\
\hline Men & $255(85 \%)$ & $117(47.4 \%)$ & $76(30.8 \%)$ & $54(21.9 \%)$ & .9757 \\
\hline Age $>70 y$ & $77(25.7 \%)$ & $38(50.7 \%)$ & $21(28 \%)$ & $16(21.3 \%)$ & .7635 \\
\hline Body mass index $\left(\mathrm{kg} / \mathrm{m}^{2}\right)$ & & & & & .2237 \\
\hline$<18.5$ & $25(8.6 \%)$ & $15(62.5 \%)$ & $5(20.8 \%)$ & $4(16.7 \%)$ & \\
\hline $18.5-25$ & $151(51.7 \%)$ & $59(40.7 \%)$ & $49(33.8 \%)$ & $37(25.5 \%)$ & \\
\hline$\geq 25$ & $116(39.7 \%)$ & $59(51.3 \%)$ & $35(30.4 \%)$ & $21(18.3 \%)$ & \\
\hline \multicolumn{6}{|l|}{ Smoking history } \\
\hline Past or present smoking & $284(94.7 \%)$ & $128(46.7 \%)$ & $85(31 \%)$ & $61(22.3 \%)$ & .9417 \\
\hline Cessation $\geq 2$ wk before surgery & $167(59.2 \%)$ & $74(46.2 \%)$ & $48(30 \%)$ & $38(23.8 \%)$ & .6975 \\
\hline \multicolumn{6}{|l|}{ Comorbid illness } \\
\hline Alcohol abuse & $84(28.1 \%)$ & $42(50.6 \%)$ & $29(34.9 \%)$ & $12(14.5 \%)$ & .1233 \\
\hline Diabetes mellitus & $38(13.7 \%)$ & $17(44.7 \%)$ & $11(28.9 \%)$ & $10(26.3 \%)$ & .9236 \\
\hline Angina history & $33(16 \%)$ & $16(48.5 \%)$ & $12(36.4 \%)$ & $5(15.2 \%)$ & .4842 \\
\hline Stroke & $13(6.3 \%)$ & $10(76.9 \%)$ & $2(15.4 \%)$ & $1(7.7 \%)$ & .2204 \\
\hline Lower limb atheroma & $29(14 \%)$ & $18(62.1 \%)$ & $9(31 \%)$ & $2(6.9 \%)$ & .142 \\
\hline \multicolumn{6}{|l|}{ Respiratory status } \\
\hline Chronic bronchitis & $201(67 \%)$ & $92(47.9 \%)$ & $58(30.2 \%)$ & $42(21.9 \%)$ & .9338 \\
\hline Chronic obstructive pulmonary disease & $198(66.4 \%)$ & $80(41.5 \%)$ & $64(33.2 \%)$ & $49(25.4 \%)$ & .0186 \\
\hline \multicolumn{6}{|l|}{ American Society of Anesthesiologists score } \\
\hline I or II & $190(64.8 \%)$ & $87(47.3 \%)$ & $52(28.3 \%)$ & $45(24.5 \%)$ & .4085 \\
\hline III or IV & $103(35.2 \%)$ & $46(46 \%)$ & $35(35 \%)$ & $19(19 \%)$ & \\
\hline Albumin $<40 \mathrm{~g} / \mathrm{L}$ & $63(22.8 \%)$ & $11(17.7 \%)$ & $15(24.2 \%)$ & $36(58.1 \%)$ & $<.0001$ \\
\hline Prealbumin $<200 \mathrm{mg} / \mathrm{L}$ & $45(18.4 \%)$ & $5(11.4 \%)$ & $12(27.3 \%)$ & $27(61.4 \%)$ & $<.0001$ \\
\hline Right-sided procedure & $178(59.3 \%)$ & $84(49.4 \%)$ & $53(31.2 \%)$ & $33(19.4 \%)$ & .3929 \\
\hline \multicolumn{6}{|l|}{ Type of resection } \\
\hline Lobectomy or bilobectomy & $230(76.7 \%)$ & $112(49.8 \%)$ & $70(31.1 \%)$ & $43(19.1 \%)$ & .0582 \\
\hline Pneumonectomy & $70(23.3 \%)$ & $24(37.5 \%)$ & $19(29.7 \%)$ & $21(32.8 \%)$ & \\
\hline Chest wall resection or parietal pleura & $18(6 \%)$ & $6(33.3 \%)$ & $3(16.7 \%)$ & $9(50 \%)$ & .0241 \\
\hline Histologic type & & $2(100 \%)$ & $0(0 \%)$ & $0(0 \%)$ & .0209 \\
\hline Epidermoid carcinoma & $119(39.7 \%)$ & $45(39.5 \%)$ & $37(32.5 \%)$ & $32(28.1 \%)$ & \\
\hline Adenocarcinoma & $120(40 \%)$ & $61(52.6 \%)$ & $42(36.2 \%)$ & $13(11.2 \%)$ & \\
\hline Basaloid carcinoma & $1(0.3 \%)$ & $0(0 \%)$ & $0(0 \%)$ & $1(100 \%)$ & \\
\hline Bronchoalveolar carcinoma & $11(3.7 \%)$ & $7(63.6 \%)$ & $2(18.2 \%)$ & $2(18.2 \%)$ & \\
\hline Large cell carcinoma & $38(12.7 \%)$ & $16(44.4 \%)$ & $8(22.2 \%)$ & $12(33.3 \%)$ & \\
\hline Mixed carcinoma & $6(2 \%)$ & $3(50 \%)$ & $0(0 \%)$ & $3(50 \%)$ & \\
\hline Large cell neuroendocrine carcinoma & $3(1 \%)$ & $2(66.7 \%)$ & $0(0 \%)$ & $1(33.3 \%)$ & \\
\hline Pathologic stage & & & & & .0029 \\
\hline I & $126(42.4 \%)$ & $74(60.7 \%)$ & $31(25.4 \%)$ & $17(13.9 \%)$ & \\
\hline II & $67(22.6 \%)$ & $25(37.3 \%)$ & $21(31.3 \%)$ & $21(31.3 \%)$ & \\
\hline III & $92(31 \%)$ & $33(38.4 \%)$ & $32(37.2 \%)$ & $21(24.4 \%)$ & \\
\hline IV & $12(4 \%)$ & $3(27.3 \%)$ & $3(27.3 \%)$ & $5(45.5 \%)$ & \\
\hline \multicolumn{6}{|l|}{ Microvascular invasion } \\
\hline Vascular emboli & $130(43.6 \%)$ & $2(100 \%)$ & $51(40.2 \%)$ & $50(31.2 \%)$ & .0433 \\
\hline Lymphatic emboli & $76(25.6 \%)$ & $32(43.2 \%)$ & $26(35.1 \%)$ & $16(21.6 \%)$ & .67 \\
\hline
\end{tabular}

All data represent numbers and percentages of patients.

disease ( $n=68)$, which was diagnosed on the basis of mediastinoscopy $(\mathrm{n}=48)$, transtracheal needle aspiration $(\mathrm{n}=4)$, or imaging $(\mathrm{n}=16)$. All chemotherapy protocols were platinum based. Operative mortality was $6.3 \%$ $(\mathrm{n}=19)$.

Table 1 summarizes the main preoperative characteristics and surgical and pathologic data, including CRP levels, of all patients. CRP level of $3 \mathrm{mg} / \mathrm{L}$ or less was found in 136 patients $(45.3 \%)$, and among patients with a detectable CRP $(\mathrm{n}=153), 89(29.7 \%)$ had a CRP level between 4 and $20 \mathrm{mg} / \mathrm{L}$ and $64(21.3 \%)$ had a level higher than $20 \mathrm{mg} / \mathrm{L}$. The CRP levels were associated with GOLD (Global Initiative for Chronic Obstructive Lung Disease) stage II chronic obstructive pulmonary disease $(P=.0186)$, 


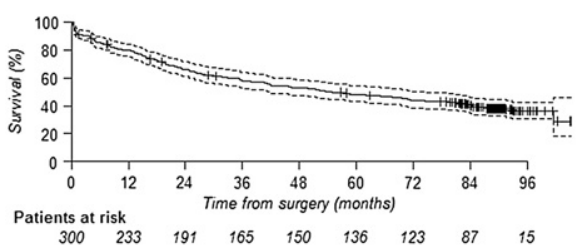

A

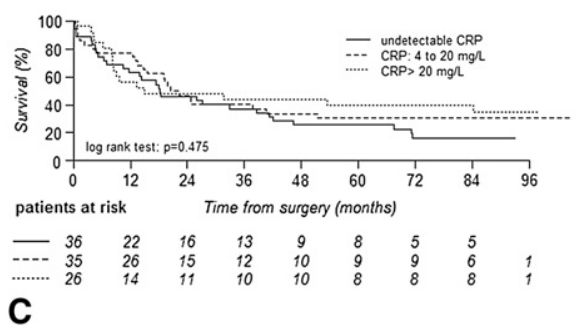

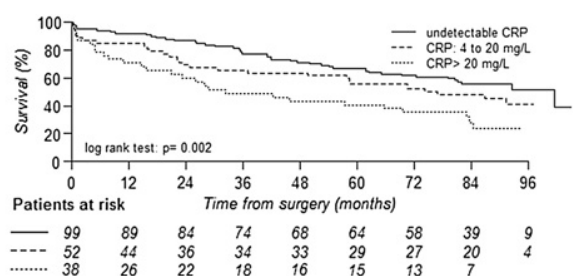

B

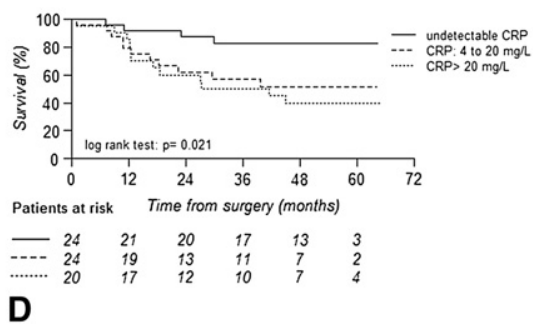

FIGURE 1. Kaplan-Meier estimates of survival. A, Overall survival in the main cohort. B, Survival curves of patients with stages I and II in the main cohort according to the C-reactive protein (CRP) levels. C, Survival curves of patients with stages III and IV in the main cohort according to the C-reactive protein levels. D, Survival curves in the validation cohort according to the C-reactive protein levels.

hypoalbuminemia $(P<.0001)$, and hypoprealbuminemia $(P<.0001)$, as well as histologic type $(P=.0209)$, pathologic stage $(P=.0029)$, microvascular invasion $(P=.0433)$, and chest wall resection $(P=.0241)$.

Long-term survival. At completion of the study (June 2010), 120 patients $(40 \%)$ were alive and $180(60 \%)$ were dead. The median follow-up duration was 89.2 months (interquartile range, 82.6-92.9 months). For the whole population, median survival was 54.9 months (95\% confidence interval [CI], 41.1-72.5 months). The $3-, 5-$, and 7-year overall survivals were $57.8 \%(95 \%$ CI, $52.4 \%-63.7 \%), 48.3 \%$ (95\% CI, $42.9 \%-54.4 \%$ ), and $44.0 \% \quad(95 \%$ CI, 38.6\%-50.1\%), respectively (Figure 1, A).

The univariate survival analysis is reported in Table 2 . Factors associated with long-term survival were chronic bronchitis $(P=.0136)$, hypoprealbuminemia $(P=.0215)$, the type of resection $(P<.0001)$, the pathologic stage $(P<.0001)$, and the presence of vascular emboli $(P=.0381)$. CRP level cutoffs of undetectable, higher than $3 \mathrm{mg} / \mathrm{L}$, and higher than $20 \mathrm{mg} / \mathrm{L}$ tended to be associated with survival $(P=.0571)$, with 5-year survivals of $55.6 \%$ (95\% CI, $47.8 \%-64.8 \%)$, $45.6 \%(95 \%$ CI, $36.2 \%-57.5 \%)$, and $40.0 \% \quad(95 \%$ CI $29.4 \%-54.4 \%$ ), respectively. Survival curves in stages I and II on the one hand and in stage III and IV on the other hand are presented in Figure 1 ( $B$ and $C$, respectively. In stages I and II, patients with an undetectable CRP had a better survival than did those with a CRP greater than $20 \mathrm{mg} / \mathrm{L}$ and those with a CRP between 4 and $20(P=.00245)$. In stages III and IV, survival was not significantly different among the CRP levels $(P=.475)$.

The results of the multivariate analysis are presented in Table 3. Stage III-IV $(P=.0010)$, pneumonectomy
$(P=.0008), \mathrm{CRP}$ greater than $20 \mathrm{mg} / \mathrm{L}(P=.0368)$, and American Society of Anesthesiologists score III-IV $(P \geq .0270)$ were independent predictors of death in the whole population. There was a statistically significant interaction between CRP level and stage of the cancer. Table 4 shows the adjusted hazard ratios for CRP levels according to the stage of the cancer. In stages I and II, the patients with CRP greater than $20 \mathrm{mg} / \mathrm{L}$ had a significantly increased adjusted hazard ratio of 1.874 (95\% CI, 1.039-3.381) relative to patients with undetectable CRP, and those with a CRP between 4 and $20 \mathrm{mg} / \mathrm{L}$ had a nonsignificantly increased hazard ratio of 1.364 (95\% CI, 0.824-2.257). In stages III and IV, the association was inverse but not significant: patients with a CRP greater than $20 \mathrm{mg} / \mathrm{L}$ had a lower adjusted hazard ratio of 0.492 (95\% CI, $0.233-$ 1.039) relative to those with undetectable CRP.

\section{Validation Cohort}

Sixty-eight patients were evaluated in the validation cohort. There were 11 women and 57 men. Mean age was $62.2 \pm 9.9$ years. Ten pneumonectomies and 58 lobectomies or bilobectomies were performed for NSCLC. Histologic types were epidermoid carcinoma, adenocarcinoma, large cell carcinoma, bronchoalveolar carcinoma, mixed carcinoma, and large cell neuroendocrine carcinoma in 29, 23, 7, 6, 2, and 1 patients, respectively. Pathologic stages were IA, IB, IIA, IIB, IIIA, IIIB, and IV in 13, 14, 1, 8, 23, 5, and 2 cases, respectively.

CRP values of $3 \mathrm{mg} / \mathrm{L}$ or less were found in $24(35.3 \%)$ of 68 patients, 25 patients had a CRP value between 4 and $20 \mathrm{mg} / \mathrm{L}$, and 20 had a CRP value greater than $20 \mathrm{mg} / \mathrm{L}$. The median of the detectable CRP values was $17.5 \mathrm{mg} / \mathrm{L}$ (interquartile range $10-60.5 \mathrm{mg} / \mathrm{L}$ ). 
TABLE 2. Effects of clinical, laboratory, and pathologic parameters on survival in the whole population of the main cohort: Univariate analysis

\begin{tabular}{|c|c|c|c|c|}
\hline Variable & Survival & Lower & Upper & $P$ value \\
\hline Age & & & & .095 \\
\hline$\leq 70 \mathrm{y}$ & 0.508 & 0.445 & 0.579 & \\
\hline$>70 \mathrm{y}$ & 0.41 & 0.312 & 0.539 & \\
\hline Body mass index & & & & .104 \\
\hline$<18.5 \mathrm{~kg} / \mathrm{m}^{2}$ & 0.477 & 0.315 & 0.721 & \\
\hline $18.5-24.99 \mathrm{~kg} / \mathrm{m}^{2}$ & 0.44 & 0.367 & 0.528 & \\
\hline$\geq 25 \mathrm{~kg} / \mathrm{m}^{2}$ & 0.544 & 0.459 & 0.645 & \\
\hline Sex & & & & .2707 \\
\hline Men & 0.469 & 0.411 & 0.536 & \\
\hline Women & 0.562 & 0.432 & 0.732 & \\
\hline Chronic bronchitis & & & & .0136 \\
\hline Yes & 0.433 & 0.368 & 0.508 & \\
\hline No & 0.586 & 0.495 & 0.693 & \\
\hline Albumin & & & & .0506 \\
\hline$<40 \mathrm{~g} / \mathrm{L}$ & 0.39 & 0.283 & 0.538 & \\
\hline$\geq 40 \mathrm{~g} / \mathrm{L}$ & 0.523 & 0.46 & 0.596 & \\
\hline Prealbumin & & & & .0215 \\
\hline$<200 \mathrm{mg} / \mathrm{L}$ & 0.368 & 0.248 & 0.547 & \\
\hline$\geq 200 \mathrm{mg} / \mathrm{L}$ & 0.534 & 0.468 & 0.609 & \\
\hline $\begin{array}{l}\text { Chronic obstructive } \\
\text { pulmonary disease }\end{array}$ & & & & .8185 \\
\hline No & 0.472 & 0.382 & 0.583 & \\
\hline Yes & 0.488 & 0.423 & 0.564 & \\
\hline Current or past smoker & & & & .1979 \\
\hline Yes & 0.478 & 0.422 & 0.541 & \\
\hline No & 0.591 & 0.384 & 0.91 & \\
\hline Atheroma & & & & .2792 \\
\hline No & 0.435 & 0.316 & 0.599 & \\
\hline Yes & 0.51 & 0.439 & 0.591 & \\
\hline $\begin{array}{l}\text { American Society of } \\
\text { Anesthesiologists score }\end{array}$ & & & & .0131 \\
\hline I or II & 0.526 & 0.459 & 0.603 & \\
\hline III or IV & 0.394 & 0.308 & 0.504 & \\
\hline Resection & & & & $<.0001$ \\
\hline Lobectomy or bilobectomy & 0.549 & 0.488 & 0.618 & \\
\hline Pneumonectomy & 0.261 & 0.173 & 0.392 & \\
\hline C-reactive protein & & & & .0571 \\
\hline Undetectable & 0.556 & 0.478 & 0.648 & \\
\hline 4-20 mg/L & 0.456 & 0.362 & 0.575 & \\
\hline$>20 \mathrm{mg} / \mathrm{L}$ & 0.400 & 0.294 & 0.544 & \\
\hline Pathologic stage & & & & $<.0001$ \\
\hline I & 0.696 & 0.62 & 0.782 & \\
\hline II & 0.381 & 0.279 & 0.521 & \\
\hline III or IV & 0.287 & 0.21 & 0.393 & \\
\hline Histologic type & & & & .8353 \\
\hline Nonepidermoid & 0.496 & 0.427 & 0.577 & \\
\hline Epidermoid & 0.471 & 0.388 & 0.571 & \\
\hline Vascular emboli & & & & .0381 \\
\hline No & 0.554 & 0.483 & 0.636 & \\
\hline Yes & 0.398 & 0.321 & 0.494 & \\
\hline Lymphatic emboli & & & & .1179 \\
\hline No & 0.514 & 0.452 & 0.586 & \\
\hline Yes & 0.403 & 0.305 & 0.533 & \\
\hline
\end{tabular}

TABLE 3. Survival multivariate analysis based on a Cox model in the whole sample

\section{SE}

Coefficient (coefficient) $P$ values

Stage

$\begin{array}{llll}\text { III or IV vs I or II } & 0.920 & 0.279 & .0010\end{array}$

Type of surgery

$\begin{array}{llll}\text { Pneumonectomy vs } & 0.682 & 0.204 & .0008\end{array}$

lobectomy or bilobectomy

American Society of Anesthesiologists score

III or IV vs I or II

\begin{tabular}{ccc}
$\mathrm{e}$ & 0.190 & .0270 \\
0.310 & 0.257 & .2276 \\
0.628 & 0.301 & .0368 \\
& & \\
-0.081 & 0.178 & .6497 \\
0.360 & 0.313 & .2499 \\
& & \\
0.078 & 0.201 & .7001 \\
0.030 & 0.199 & .8786 \\
& & \\
0.263 & 0.182 & .1490 \\
& & .1550 \\
0.852 & 0.599 & .1048 \\
0.324 & 0.200 & .9876 \\
& & .5278 \\
0.006 & 0.378 & .1096 \\
0.483 & 0.765 & \\
& & \\
0.636 & 0.398 & \\
-1.338 & 0.438 & \\
\hline
\end{tabular}

C-reactive protein

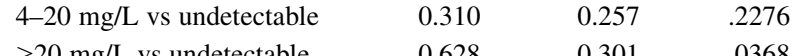

$>20 \mathrm{mg} / \mathrm{L}$ vs undetectable

Body mass index

$>25 \mathrm{~kg} / \mathrm{m}^{2}$ vs $18.5-25 \mathrm{~kg} / \mathrm{m}^{2} \quad-0.081 \quad 0.178 \quad .6497$

$\leq 18.5$ vs $>18.5-25 \mathrm{~kg} / \mathrm{m}^{2} \quad 0.360 \quad 0.313 \quad .2499$

Age

$>70$ y vs $\leq 70$ y

Lymphatic emboli

Yes vs no

Vascular emboli

Yes vs no

Smoking status

Smoker vs not a smoker

Chronic bronchitis

Yes vs no

Albumin

$<40 \mathrm{~g} / \mathrm{L}$ vs $\geq 40 \mathrm{~g} / \mathrm{L}$

Propensity score

Interactions with stage III or IV

C-reactive protein $4-20 \mathrm{mg} / \mathrm{L}$

C-reactive protein $>20 \mathrm{mg} / \mathrm{L}$

$-1.338$

0023

Age $(P=.32)$, sex $(P=.84)$, extent of resection $(P=.21)$, and histologic type (epidermoid vs adenocarcinoma or large cell carcinoma, $P=.069)$ failed to be associated with survival. Stage $(P=.012)$ and CRP level $(P=.021)$ were predictors of survival in univariate analysis. Patients with CRP levels of $3 \mathrm{mg} / \mathrm{L}$ or less had a 5-year survival of $82.7 \%$ (95\% CI, 62.9\%-93.1\%), as compared with 51.7\% (95\% CI, 34.6\%-77.4\%) and 40.0\% (95\% CI, $23.4 \%-68.4 \%$ ) for patients with a CRP between 4 and $20 \mathrm{mg} / \mathrm{L}$ and those with a CRP greater than $20 \mathrm{mg} / \mathrm{L}$, respectively $(P=.021)$. After adjustment with the pathologic stage, the association between worse survival and CRP levels was maintained only between patients with undetectable CRP and patients with CRP greater than $20 \mathrm{mg} / \mathrm{L}$ $(P=.018)$ and was lost between patients with a CRP between 4 and $20(P=.12)$ and those with an undetectable CRP.

\section{DISCUSSION}

This large study found that CRP level is an independent predictor of long-term survival in patients with initial stage 
TABLE 4. Adjusted hazard ratios calculated from the multivariate analysis, taking into account the interaction between $C$-reactive protein levels and pathologic stage

\begin{tabular}{lcc}
\hline C-reactive protein level & Stage I or II & Stage III or IV \\
\hline 4-20 mg/L vs undetectable & $1.364(0.824-2.257)$ & $0.722(0.395-1.319)$ \\
$>20 \mathrm{vs}$ undetectable & $1.874(1.039-3.381)$ & $0.492(0.233-1.039)$ \\
\hline Figures are hazard ratios with 95\% confidence intervals. Adjustments were done for \\
age, propensity score for C-reactive protein greater than $20 \mathrm{mg} / \mathrm{L}$, vascular and \\
lymphatic emboli, type of surgery, chronic bronchitis, American Society of Anesthe- \\
siologists score, albuminemia, smoking status, pathologic stage, and interaction \\
between C-reactive protein level and pathologic stage.
\end{tabular}

resected NSCLC. This suggests that systemic inflammation is related to outcome in these patients. These results are based on the study of 2 cohorts from 2 different surgical centers: in the first, preoperative and early postoperative data were prospectively collected, whereas survival data were retrospectively obtained; in the validation cohort, both preoperative and postoperative data were collected retrospectively.

\section{Strengths and Limitations of the Study}

In our opinion, a main strength of the study was the high number of consecutive patients evaluated in the main cohort with a standardized case report form that included a large number of clinical and laboratory parameters that are not usually measured in patients undergoing surgery for lung cancer. On the other hand, the retrospective character of the data collection prevented us from obtaining precise information on disease relapse after surgery. Overall survival, rather than progression-free survival, was therefore evaluated. Furthermore, missing data led us to exclude some potentially eligible patients. This limitation concerned only a minority of patients, however, and is therefore unlikely to have affected the results.

Abnormal CRP values ( $>3 \mathrm{mg} / \mathrm{L})$, indicating some degree of systemic inflammation, were present in approximately half of operable patients with operable disease. This parameter could thus constitute the basis for development of specific management strategy in a significant proportion of cases. In the Japanese study by Hara and colleageus, ${ }^{15}$ only 38 out of the 203 surgically treated patients $(18.7 \%)$ were found to have abnormal CRP values; however, their cutoff was set at $5 \mathrm{mg} / \mathrm{L}$.

\section{CRP Levels and Tumor Size}

In our experience, the number of patients with increased CRP levels was relatively low in stage IA NSCLC $(29 \%$ and $33 \%$ in the main and validation cohorts, respectively) but increased dramatically in stage IB (57\% and $78 \%$ in the main and validation cohorts, respectively). Although this finding is in agreement with the known relationship between CRP levels and primary tumor burden, ${ }^{19}$ the prognostic value of both CRP level and pT persisted in multivariate analysis, suggesting that the predictive values of these 2 features are at least in part independent. As already reported by others, ${ }^{19}$ we did not find a correlation between CRP and $\mathrm{pN}$ and $\mathrm{pM}$ parameters.

\section{CRP as a Prognostic Factor in Resected NSCLC}

High CRP levels were a marker of poor prognosis in patients with stage I and II disease. Comparison with the available literature is difficult, because only a few studies have assessed the prognostic value of CRP in resected lung cancer. In these studies, ${ }^{15,16}$ prognostic significance was demonstrated in the whole population but an analysis per stage was unavailable, probably because of the relatively low number of patients in each category.

\section{Underlying Mechanisms}

In a large cohort study of 10,408 individuals, it was recently shown that elevated CRP levels in cancer-free subjects were associated with an increased risk of subsequent occurrence of cancer, particularly lung cancer. ${ }^{4}$ The mechanisms underlying this association have not been elucidated. In particular, the cohort studies do not allow one to differentiate between whether systemic inflammation and CRP levels are markers of occult cancer or are causally related to the malignancy. ${ }^{6}$ A more recent analysis of the same cohorts, however, based on the mendelian randomization approach of 4 common single-nucleotide polymorphisms, suggests that elevated CRP levels do not cause cancer per se. ${ }^{20}$ Thus in cancer-free patients, high levels of CRP might relate to occult cancers. Interestingly, in that study, increased baseline CRP levels were associated with early death after diagnosis of any cancer in patients without metastatic disease at diagnosis. ${ }^{4}$

In our study, CRP levels were significantly correlated with tumoral vascular emboli. Blood vessel invasion is known to be crucial for tumor spread, and it as been suggested that vascular invasion could be an indicator of occult metastases in early stages. Lee and associates ${ }^{19}$ also found that tumor size and vascular invasion were independently associated with CRP levels in a multiple linear regression analysis. The mechanisms underlying this association remain poorly explained. The role of proinflammatory cytokine secretion by endothelial cells encountering tumor cells could be an interesting hypothesis. ${ }^{19}$

Other mechanisms explaining the prognostic role of CRP have been advocated. CRP could be a marker of tumor production of interleukin 6, which is known to block p53induced apoptosis. ${ }^{15}$ Thus increased CRP levels could be a marker of the ability of tumors to maintain a microenvironment suitable for the survival of remnant cells through the upregulation of some acute inflammatory cytokines. ${ }^{15}$

Another possible explanation of the prognostic value of CRP could be the relationship between systemic inflammation and nutritional status. ${ }^{7}$ Systemic inflammation has deleterious effects through the catabolic effects of cytokines 
and acute-phase proteins, which increase resting energy expenditure. Indeed, in our experience prealbumin levels and Prognostic Inflammatory and Nutrition Index (which correlated negatively with CRP, data not shown) were predictors of survival in univariate analysis, although their prognostic value did not persist in multivariate analysis. This finding suggests that nutritional derangement is a less robust determinant of prognosis than is preoperative CRP level.

\section{Perspectives}

Patients with initial stage NSCLC are best treated with surgery when possible, but at present there is no consensus regarding the usefulness of postoperative follow-up. Repeated chest radiography, CT scan, fiberoptic bronchoscopy, and positron emission tomographic scan have been proposed, with enormous variations in medical resource use and costs, as well as generation of patient stress. On the other hand, adjuvant chemotherapy is known to improve survival for patients with stage II or IIIa resected NSCLC, although it provides no survival advantage for patients with stage Ia disease. Results remain controversial for stage Ib disease. ${ }^{21}$

Identification of patients with poor prognosis within a determined stage would thus be useful for individual tailoring of postoperative management. CRP measurement, together with available clinicopathologic parameters, could help in identifying patients requiring more aggressive management. This potential utility remains to be formally demonstrated in adequately designed studies.

We are grateful to Mrs Beatrice Marmey and Mrs Patricia Bonjour for precious technical assistance. M.A. cared for patients of the main cohort, conceived the study, analyzed data, and wrote the paper. P.E.F. cared for patients of the validation cohort and contributed to study conception and hypothesis delineation. V.S. analyzed data. N.R. was involved in the design of the study and in manuscript writing. O.S. prospectively collected preoperative data and cared for patients in the main cohort. M.Y. collected data on long-term survival. F.A. collected preoperative and survival data of the validation cohort. P.F. was involved in the conception of the study and hypothesis delineation. A.D. analyzed data and contributed to writing the paper. G.M. cared for patients of the validation cohort and was involved in the conception of the study. D.D. contributed to study conception and hypothesis delineation. J-F.R. cared for patients of main cohort and was involved in the conception of the study.

\section{References}

1. McMillan DC. Systemic inflammation, nutritional status and survival in patients with cancer. Curr Opin Clin Nutr Metab Care. 2009;12:223-6.

2. Balkwill F, Mantovani A. Cancer and inflammation: implications for pharmacology and therapeutics. Clin Pharmacol Ther. 2010;87:401-6.

3. Lazennec G, Richmond A. Chemokines and chemokine receptors: new insights into cancer-related inflammation. Trends Mol Med. 2010;16:133-44.

4. Allin KH, Bojesen SE, Nordestgaard BG. Baseline C-reactive protein is associated with incident cancer and survival in patients with cancer. J Clin Oncol. 2009; 27:2217-24

5. Alberg AJ, Ford JG, Samet JM. Epidemiology of lung cancer: ACCP evidencebased clinical practice guidelines (2nd edition). Chest. 2007;132(3 Suppl):29S-55.

6. Barnes PJ, Celli BR. Systemic manifestations and comorbidities of COPD. Eur Respir J. 2009;33:1165-85.

7. Pepys MB, Hirschfield GM. C-reactive protein: a critical update. J Clin Invest. 2003;111:1805-12. Erratum in: J Clin Invest. 2003;112:299.

8. Matsuguchi T, Okamura S, Kawasaki C, Shimoda K, Omori F, Hayashi S, et al. Constitutive production of granulocyte colony-stimulating factor and interleukin- 6 by a human lung cancer cell line, KSNY: gene amplification and increased mRNA stability. Eur J Haematol. 1991;47:128-33.

9. Haura EB, Livingston S, Coppola D. Autocrine interleukin-6/interleukin-6 receptor stimulation in non-small-cell lung cancer. Clin Lung Cancer. 2006;7:273-5.

10. Niiya M, Niiya K, Kiguchi T, Shibakura M, Asaumi N, Shinagawa K, et al. In duction of TNF-alpha, uPA, IL-8 and MCP-1 by doxorubicin in human lung carcinoma cells. Cancer Chemother Pharmacol. 2003;52:391-8.

11. McMillan DC, Elahi MM, Sattar N, Angerson WJ, Johnstone J, McArdle CS. Measurement of the systemic inflammatory response predicts cancer-specific and non-cancer survival in patients with cancer. Nutr Cancer. 2001;41:64-9.

12. Elahi MM, McMillan DC, McArdle CS, Angerson WJ, Sattar N. Score based on hypoalbuminemia and elevated C-reactive protein predicts survival in patients with advanced gastrointestinal cancer. Nutr Cancer. 2004;48:171-3.

13. Wilop S, Crysandt M, Bendel M, Mahnken AH, Osieka R, Jost E. Correlation of $\mathrm{C}$-reactive protein with survival and radiographic response to first-line platinumbased chemotherapy in advanced non-small cell lung cancer. Onkologie. 2008; 31:665-70.

14. Koch A, Fohlin H, Sörenson S. Prognostic significance of C-reactive protein and smoking in patients with advanced non-small cell lung cancer treated with firstline palliative chemotherapy. J Thorac Oncol. 2009;4:326-32.

15. Hara M, Matsuzaki Y, Shimuzu T, Tomita M, Ayabe T, Enomoto Y, et al. Preoperative serum C-reactive protein level in non-small cell lung cancer. Anticancer Res. 2007;27:3001-4.

16. O’Dowd C, McRae LA, McMillan DC, Kirk A, Milroy R. Elevated preoperative C-reactive protein predicts poor cancer specific survival in patients undergoing resection for non-small cell lung cancer. $J$ Thorac Oncol. 2010;5:988-92.

17. Schussler O, Alifano M, Dermine H, Strano S, Casetta A, Sepulveda S, et al. Postoperative pneumonia after major lung resection. Am J Respir Crit Care Med. 2006;173:1161-9.

18. Schussler O, Dermine H, Alifano M, Casetta A, Coignard S, Roche N, et al Should we change antibiotic prophylaxis for lung surgery? Postoperative pneumonia is the critical issue. Ann Thorac Surg. 2008;86:1727-33.

19. Lee JG, Cho BC, Bae MK, Lee CY, Park IK, Kim DJ, et al. Preoperative C-reactive protein levels are associated with tumor size and lymphovascular invasion in resected non-small cell lung cancer. Lung Cancer. 2009;63:106-10.

20. Allin KH, Nordestgaard BG, Zacho J, Tybjaerg-Hansen A, Bojesen SE. C-reactive protein and the risk of cancer: a mendelian randomization study. J Natl Cancer Inst. 2010;102:202-6.

21. Wakelee HA, Schiller JH, Gandara DR. Current status of adjuvant chemotherapy for stage IB non-small-cell lung cancer: implications for the New Intergroup Trial. Clin Lung Cancer. 2006;8:18-21. 